\title{
Growth and metabolic consequences of growth hormone treatment in prepubertal short normal children
}

\author{
E S McCaughey, J Mulligan, L D Voss, P R Betts
}

\begin{abstract}
Growth and the metabolic effects of growth hormone were monitored in a randomised, controlled group of 41 short, normal, prepubertal children. The treated group received daily injections of growth hormone as Genotropin (Kabi Pharmacia) $30 \mathrm{IU} / \mathrm{m}^{2} /$ week. Fifteen children in the treated group ( 21 children) have completed three years of treatment, have grown significantly more than 14 (of 20) untreated children, and have a significantly greater adult height prediction. They do, however, remain leaner (body fat $13.5 \%$ in the treated group, $18 \%$ in the untreated group) and relatively hyperinsulinaemic (insulin $66.7 \mathrm{pmol} / \mathrm{l}$ in the treated group, 44.5 in the untreated group) after three years compared with untreated children. Although growth hormone appears to improve the height potential of prepubertal short normal children, the long term outcome is still uncertain.

(Arch Dis Child 1994; 71: 201-206)
\end{abstract}

When synthetic growth hormone became available in 1985, there was the potential for much wider clinical applications. No longer restricted to children with proved growth hormone deficiency, the use of growth hormone to treat short normal children has been controversial and a source of continuing debate. ${ }^{1}$ According to the Kabi International Growth Study (KIGS) report, one in 10 children now receiving growth hormone treatment in the UK has idiopathic short stature. ${ }^{2}$ In the short term, growth hormone significantly increases height velocity in such children, ${ }^{3-8}$ but the long term outcome in terms of final adult height, metabolic effects, and psychological status is still unclear. If a positive outcome is shown, then identifying the factors which predict a good response to growth hormone would help to decide which children should be offered growth hormone treatment.

To resolve these issues, scientifically conducted, properly designed, controlled trials are needed to clarify the indications for treatment and to prevent the widespread use of growth hormone, if there is no proved benefit.

It was the purpose of this study to monitor closely the physical progress and the metabolic and psychological responses through childhood and puberty of a group of similarly aged, short children treated with growth hormone, and to compare them with an untreated group of short normal controls. Psychological responses will be reported separately.

A striking increase in height velocity after the first six months of treatment has already been reported and concern expressed about the implications of the marked lipolytic effect of growth hormone on body composition. ${ }^{9}$ This paper reports the continued progress of the trial over the first three years during the prepubertal phase.

\section{Patients and methods}

Forty onề short, normal children, of similar age and social class, whose heights were more than two standard deviations (SDs) below the mean according to the Tanner and Whitehouse standards, ${ }^{10}$ and who had an adequate stimulated growth hormone response, were entered into the trial. All the children had a stimulated growth hormone concentration greater than $7.5 \mu \mathrm{g} / \mathrm{l}(15 \mathrm{mU} / \mathrm{/})$ to either clonidine or sleep, or both, ranging from $7 \cdot 7$ to $38.3 \mu \mathrm{g} / \mathrm{l}(15.4$ to $76.5 \mathrm{mU} / \mathrm{l}$ ). Only one child had a maximum stimulated growth hormone response between 7.5 and $10 \mu \mathrm{g} / \mathrm{l}$ (15 and $20 \mathrm{mU} / \mathrm{l})$. Clinical examination and screening tests had already excluded any known pathology or recognisable causes of short stature. The subjects were randomly allocated either to the treated group $(n=21)$ or to the untreated group $(n=20)$.

\section{PATIENT CHARACTERISTICS}

The mean (SD) age at the onset of the trial was $7 \cdot 8(0.5)$ years. There was a similar sex distribution with 11 boys and 10 girls in the treated group, and 12 boys and eight girls in the untreated group.

The mean birth weight for the two groups was similar, $2800 \mathrm{~g}$ in the treated and $2813 \mathrm{~g}$ in the untreated group. Two children in each group had birth weights below the third centile for gestational age. There was no difference between groups for admission rates to the special care baby unit.

On detailed comparison there was no difference between the treated and untreated groups at the onset of the trial with respect to age, sex, height, parental height, birth details, bone age delay, socioeconomic status, or evidence of psychosocial deprivation.

\section{TREATMENT REGIMEN}

The treated group received recombinant human growth hormone, Genotropin, $30 \mathrm{IU} / \mathrm{m}^{2} /$ week (Kabi Pharmacia) as daily 


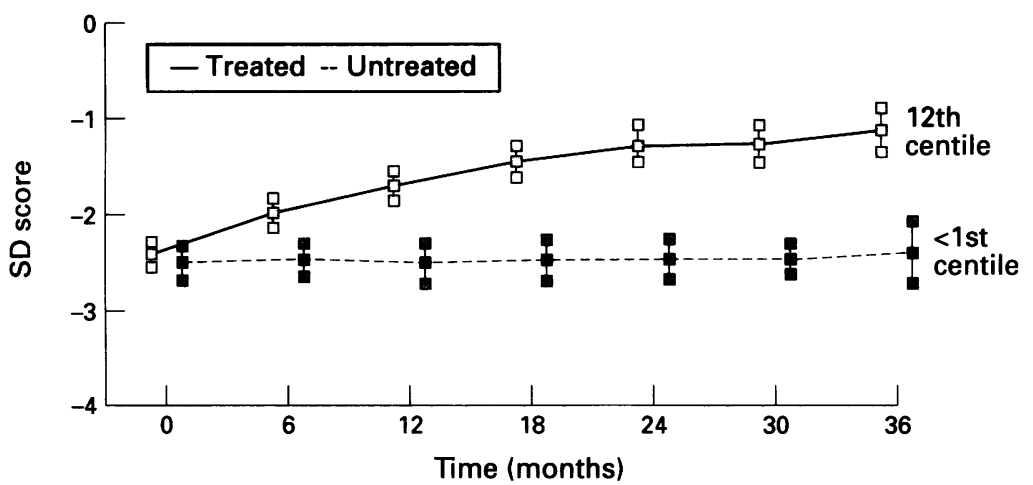

Figure 1 Mean (SEM) height SD score for chronological age in treated and untreated children.

subcutaneous injections using an Autoinjector (Owen Mumford).

\section{AUXOLOGY}

In the two groups, the following anthropometric measurements were made every six months: height, weight, and sitting height. Height, including pretreatment height, was measured by a single observer (LV) using an electronic, digital stadiometer (Holtain Ltd); sitting height was measured using a similar Holtain device and weight was recorded using digital scales. No difference was found in either pretreatment height velocity or actual height between the two groups at entry into the study. Actual parental height was recorded in $100 \%$ of mothers and $50 \%$ of fathers at the beginning of the study and estimated heights noted in the remainder.

\section{BONE MATURATION}

Bone age was assessed annually by a single, external, 'blinded' auxologist using the RUS method of Tanner and Whitehouse. ${ }^{11}$ Adult height predictions were made every 12 months based on bone age, chronological age, and height using Tanner's equation, TW 2 mark 2 version.

\section{BODY COMPOSITION}

Skinfold thickness measurements were taken from four sites (biceps, triceps, subscapular, and suprailiac) using Holtain calipers. Body fat was calculated from the sum of the skinfolds using the equations of Brook ${ }^{12}$ and Siri. ${ }^{13}$

\section{ECHOCARDIOGRAPHY}

This was performed annually on the two groups to measure left ventricular posterior wall and intraventricular septal thicknesses.

Table 1 Rolling 12 month velocity in treated and untreated children; figures are mean (SEM)

\begin{tabular}{|c|c|c|c|c|c|c|}
\hline \multirow{2}{*}{$\begin{array}{l}\text { Time } \\
\text { (months) }\end{array}$} & \multicolumn{2}{|c|}{ Boys (cm/year) } & \multicolumn{2}{|c|}{ Girls (cm/year) } & \multicolumn{2}{|c|}{ Both (cm/year) } \\
\hline & Treated & Untreated & Treated & Untreated & Treated & Untreated \\
\hline $\begin{array}{r}0 \\
12 \\
18 \\
24 \\
30 \\
36\end{array}$ & $\begin{array}{l}5.3(0.53) \\
9.2(0.47) \\
8.3(0.67) \\
7.4(0.41) \\
6.3(0.61) \\
5.9(0.53)\end{array}$ & $\begin{array}{l}5.3(0.73) \\
5.2(0.42) \\
5.3(0.71) \\
5.5(0.53) \\
4.7(0.69) \\
5.2(0.49)\end{array}$ & $\begin{array}{l}5.1(0.47) \\
9.0(0.66) \\
8.6(0.63) \\
8.0(1.21) \\
6.5(1.01) \\
6.8(0.89)\end{array}$ & $\begin{array}{l}5.3(0.62) \\
5.2(0.61) \\
4.9(0.86) \\
4.9(0.69) \\
4.7(0.63) \\
5.2(0.99)\end{array}$ & $\begin{array}{l}5.2(0.34) \\
9.1(0.40) \\
8.4(0.45) \\
7.7(0.67) \\
6.4(0.59) \\
6.4(0.58)\end{array}$ & $\begin{array}{l}5.3(0.47) \\
5.2(0.34) \\
5.1(0.54) \\
5.2(0.44) \\
4.7(0.45) \\
5.2(0.50)\end{array}$ \\
\hline
\end{tabular}

METABOLIC DATA

A single fasting venous blood sample was taken annually to monitor biochemical, haematological, and endocrinological parameters, including insulin, glucose, glycated haemoglobin, insulin-like growth factor (IGF-1), cholesterol, triglycerides, urea and electrolytes, liver function tests, and full blood count.

\section{COMPLIANCE}

Every effort was made to ensure and monitor compliance including bottle counts, careful checking of growth hormone prescription requirements, and observing changes in growth velocity and IGF-1 concentrations.

\section{STATISTICS}

The results are generally expressed as mean (two standard errors of the mean). Data were analysed using SPSS; statistical analysis was performed using Student's $t$ test, the MannWhitney test, and multiple regression analysis where appropriate.

\section{Results}

Fifteen children of an initial 21 treated (seven boys, eight girls) have now completed three years of growth hormone treatment. Of those who withdrew from this group, one did so immediately owing to a dislike of injections, one because she developed acne which persisted after treatment stopped, and four due to a lack of parental support. Fourteen of an initial 20 untreated children (eight boys, six girls) continue in the trial. Six children have withdrawn from intensive monitoring; one disliked annual blood tests, one developed asthma requiring steroid inhalers, two lacked parental support, and two moved out of the district. Height data, however, have been regularly collected for all children.

PUBERTY

All the boys remained prepubertal after three years in the trial, whereas four girls in each of the treated and untreated groups had just entered stage II puberty in the third year.

\section{AUXOLOGY}

There was a significant and sustained improvement in height centile from six months after treatment started in the treated group compared with the untreated group. Expressed as a SD score, the mean height of the treated group increased after three years from -2.4 to $-1 \cdot 2$ SDs (fig 1), equivalent to the 12 th centile. No change was noted in the untreated group; the height SD score remained at $-2 \cdot 4(\mathrm{p}<0.001)$. Good individual responses to treatment were noted, with heights after three years of growth hormone treatment lying between the third and 33rd centiles. The fastest phase of growth in the treated group was during the first six months of treatment, as we previously 

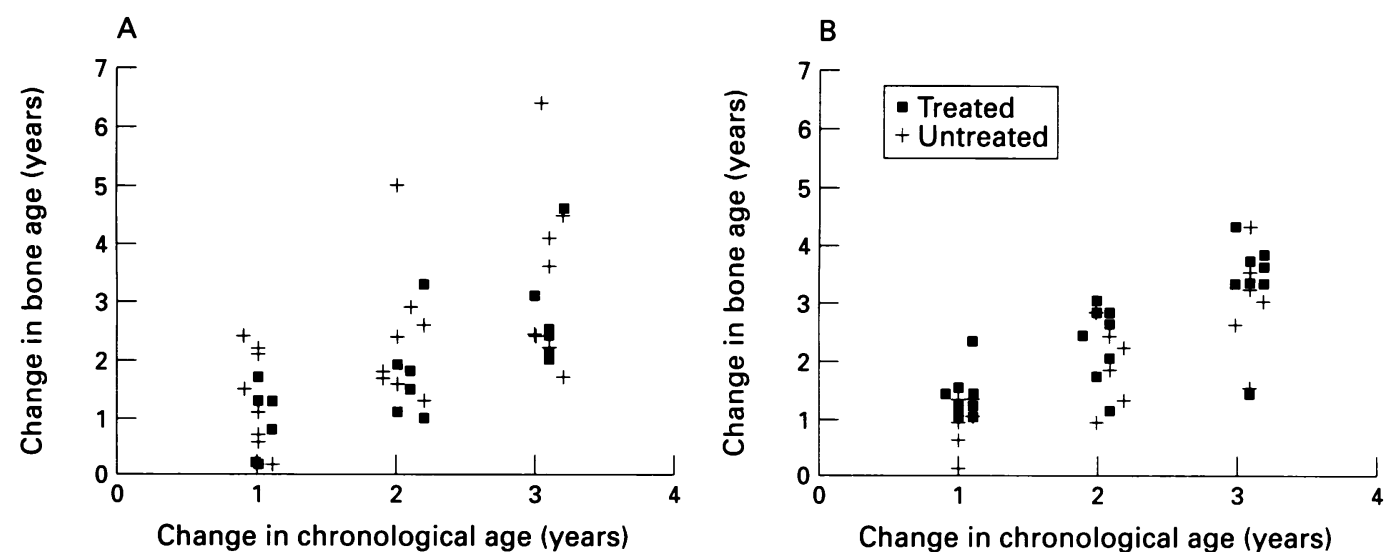

Figure 2 Individual change in bone age against change in chronological age in treated and untreated $(A)$ boys and (B) girls. Values from one treated boy missing as no baseline value.

reported, ${ }^{9}$ when the mean height velocity increased from 5.2 to $9.4 \mathrm{~cm} /$ year. After three years this group continued to grow significantly faster than the untreated group at a rate of 6.4 compared with $5.2 \mathrm{~cm} /$ year $(p<0.003)$, equivalent to a height velocity SD score of 0.74 in the treated and -0.25 in the untreated groups. The velocity data are presented in table 1 as rolling 12 month velocities - that is, every six months velocities are calculated for the preceding 12 month period. When sitting height was expressed as a ratio with standing height, the mean ratio remained at 1.8 for the treated and untreated groups at each six monthly time interval. Thus no disproportionate growth was observed.

\section{BONE MATURATION}

The initial mean (SD) bone age for the treated group was $7.9(1.1)$ years and in the untreated group was $6.6(1.0)$ years when the mean chronological age was 8.0 years for the treated and 7.6 years for the untreated group. Bone age increased appropriately for chronological age in the two groups; the mean bone age increment was 3.1 years in the treated and 3.3 years in the untreated groups, whereas the chronological age increment was $3 \cdot 1$ years in the two groups. Figure 2 shows the individual change in bone age compared with the change in chronological age. When the height SD score was corrected for bone age, it still increased significantly in the treated group over the three year treatment period from $-2 \cdot 2$ to $-1 \cdot 2$, remaining unchanged in the

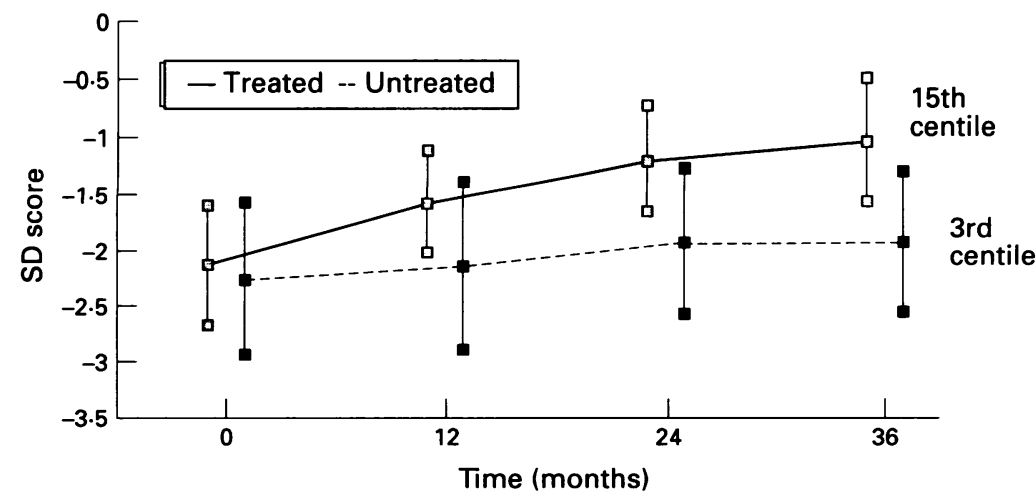

Figure 3 Mean (SEM) predicted adult height SD score in treated and untreated children. untreated group at $-1.7(p<0.0001)$. The predicted adult height for the treated group significantly improved each year $(\mathrm{p}<0.0001)$, especially for the boys, with a minimum improvement noted in the untreated group. After three years the improvement in predicted adult height was $7 \cdot 2 \mathrm{~cm}$ for all treated children $(10.3 \mathrm{~cm}$ for boys, $4.0 \mathrm{~cm}$ for girls) compared with $1.4 \mathrm{~cm}$ for all untreated children $(3.4 \mathrm{~cm}$ for boys, $-0.6 \mathrm{~cm}$ for girls). The mean predicted adult height SD score in the treated group after three years was $-1 \cdot 1$, which is equivalent to a final adult height prediction on the 15 th centile (fig 3 ).

The target height is the midparental height adjusted for sex and the target range is that within which $95 \%$ of eventual adult heights are expected to lie. ${ }^{14}$ In our treated group of children, $93 \%$ of their predicted adult heights were below the target height at entry, whereas 53\% were above it after three years of growth hormone treatment. The mean midparental height SD score was $-1 \cdot 4$, equivalent to the ninth centile.

\section{BODY COMPOSITION}

Maximum fat loss in the treated group occurred in the first six months as previously reported. ${ }^{9}$ Although gradually regaining body fat, the treated children remained significantly leaner after three years, when body fat was $13.5 \%$ compared with $17.9 \%$ in the untreated children; $\mathrm{p}<0.015$ (fig 4). Similar patterns were observed in the two sexes, although the boys, treated and untreated, were slightly leaner than the girls.

\section{ECHOCARDIOGRAPHY}

No significant change was found in left ventricular posterior wall and intraventricular septal thickness between the two groups. Further detailed analysis will be reported elsewhere.

\section{METABOLIC CHANGES}

IGF-1 increased in all children receiving growth hormone treatment and the mean levels were significantly greater than in the untreated group $(p<0.0001)$ at all times after baseline. There was a poor correlation between 


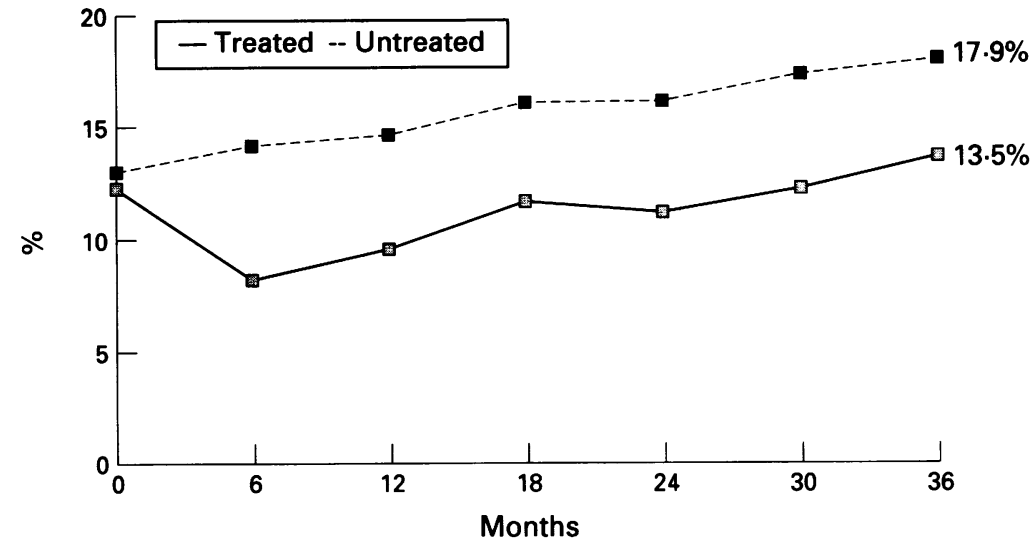

Figure 4 Mean percentage body fat in treated and untreated children.

height velocity and IGF-1 values or a change in IGF-1 in the early phase of treatment, however.

A slight increase was noted in the mean fasting blood glucose over three years in the treated group, but this was still within the normal range and not significantly different from the untreated group. No change was seen in glycated haemoglobin concentrations in either group with a mean of $6.3 \%$ in the treated and $6.6 \%$ in the untreated groups at three years.

There was a significant increase in mean fasting insulin concentrations after the first year of treatment in the treated group from $20 \cdot 8$ to $50 \cdot 2 \mathrm{pmol} / 1$ compared with a minimum increase in the untreated group from 24.4 to $31.6 \mathrm{pmol} / 1$. A continuing increase in insulin was noted annually in the treated group, which reached a mean value of $66.7 \mathrm{pmol} / \mathrm{l}$ after three years of treatment, significantly higher than in the untreated group $(p<0.01)$.

Four girls in each of the treated and untreated groups reached stage II puberty in the third year of the trial. When these girls were excluded from the insulin analysis, the mean fasting insulin for the children in stage 1 puberty was $63.9 \mathrm{pmol} / \mathrm{l}$ in the treated group, which was still significantly higher than $44 \cdot 5$ $\mathrm{pmol} / 1$ in the untreated group $(\mathrm{p}<0.01)$.

Multiple regression analysis of a number of variables against insulin including IGF-1, height, weight, change in weight, velocity, velocity SD score, bone age, sex, and an indicator of those receiving treatment, showed a significant correlation of insulin with IGF-1 only. A clear linear relation was seen between these two correlates, with significant $r$ values of 0.44 at entry and 0.66 at year $3(p<0.01)$.

Table 2 Metabolic changes (mean (2 SEM) serum values) in treated and untreated children

\begin{tabular}{|c|c|c|c|c|c|}
\hline $\begin{array}{l}\text { Times } \\
\text { (months) }\end{array}$ & $\begin{array}{c}I G F-1 \\
(\mu g / l)\end{array}$ & $\begin{array}{l}\text { Glucose } \\
\text { (mmoll) }\end{array}$ & $\begin{array}{l}\text { Insulin } \\
\text { (pmoll) }\end{array}$ & $\begin{array}{l}\text { Cholesterol } \\
\text { (mmoll) }\end{array}$ & $\begin{array}{l}\text { Triglycerides } \\
\text { (mmoll) }\end{array}$ \\
\hline \multicolumn{6}{|l|}{0} \\
\hline Treated & $131(23)$ & $4 \cdot 2(0.3)$ & $20 \cdot 8(4 \cdot 7)$ & $4.5(0.3)$ & $0.52(0.05)$ \\
\hline \multicolumn{3}{|l|}{12} & $24 \cdot 4(6 \cdot 7)$ & $4 \cdot 0(0.6)$ & $0.55(0.12)$ \\
\hline Treated & $395(74)$ & $4 \cdot 8(0 \cdot 2)$ & $50 \cdot 2(10 \cdot 3)$ & $4 \cdot 8(0.4)$ & $0.63(0.18)$ \\
\hline \multicolumn{6}{|l|}{24} \\
\hline $\begin{array}{l}\text { Treated } \\
\text { Untreated }\end{array}$ & $422(97)$ & $\begin{array}{l}4.8(0.2) \\
4.5(0.1)\end{array}$ & $\begin{array}{l}56 \cdot 7(12 \cdot 9) \\
30 \cdot 1(7 \cdot 2)\end{array}$ & $\begin{array}{l}4.8(0.3) \\
4 \cdot 1(0.4)\end{array}$ & $\begin{array}{l}0.79(0.21) \\
0.66(0.17)\end{array}$ \\
\hline \multicolumn{6}{|l|}{36} \\
\hline $\begin{array}{l}\text { Treated } \\
\text { Untreated }\end{array}$ & $\begin{array}{l}469(81) \\
200(50)\end{array}$ & $\begin{array}{l}4 \cdot 7(0 \cdot 3) \\
4 \cdot 7(0 \cdot 2)\end{array}$ & $\begin{array}{l}66 \cdot 7(13 \cdot 8) \\
44 \cdot 5(7 \cdot 2)\end{array}$ & $\begin{array}{l}4 \cdot 6(0 \cdot 2) \\
4 \cdot 4(0 \cdot 5)\end{array}$ & $\begin{array}{l}0.76(0.17) \\
0.65(0.13)\end{array}$ \\
\hline
\end{tabular}

A slight but insignificant increase was found for cholesterol and triglycerides in the treated and untreated groups, remaining within the normal range for age for our laboratory. No significant changes were noted in other biochemical or haematological parameters.

\section{FACTORS INFLUENCING RESPONSE TO}

TREATMENT

Several variables which may influence the response to treatment were considered. These included baseline factors such as chronological age, bone age SD score, initial height SD score, pretreatment height velocity, target height, birth weight and centile, sex, mother's height, and baseline IGF-1. Variables with time such as change in bone age, bone age SD score, weight and IGF-1 over three years, and velocity $S D$ score in the first 12 months were all compared with change in height SD score over three years.

When all the treated and untreated children were considered, change in weight and IGF-1 correlated significantly with change in height SD score. None of the other factors had any effect. When only the treated children were considered, however, a change in IGF-1 and weight no longer correlated significantly with growth response as assessed by a change in height SD score.

\section{Discussion}

The ultimate aim of this longitudinal study is to resolve some of the issues surrounding the place of growth hormone in the treatment of short normal children and to rationalise its use. Short term improvement in height has been shown clearly in this study and in others, ${ }^{3-8}$ but the long term outcome in terms of final adult height, safety, and wellbeing has yet to be shown.

There are a number of features which are unique to this study. The children were originally drawn from the community and not the hospital clinic and were therefore free from referral bias. The age band is narrow and there are equal numbers of each sex. The continued monitoring of an untreated control group yields additional, comparative data. One of the difficulties in the interpretation of interventional studies affecting growth and development is the dynamic nature of growth data with increasing age. Thus it is vitally important to have a matched group of control subjects to aid in such interpretation. Many other similar studies lack the continuation of such a control group.

The dose of growth hormone used in children in this study, $30 \mathrm{IU} / \mathrm{m}^{2} /$ week, is higher than the standard dose used for idiopathic growth hormone deficiency, but is that suggested for the treatment of short normal children and certain clinical disorders such as Turner's syndrome and chronic renal failure. ${ }^{15} 16$ It has been shown that a higher dose has a greater effect on growth response than lower dose regimens in the treatment of short normal children, ${ }^{36}$ although the optimum dose has not been defined. The 
frequency of daily injections six or seven times a week, as used in our study, has also been shown to be more effective than intermittent schedules. $^{517}$

A clear improvement in the rate of growth and final height potential was seen in boys and girls after the first three years of growth hormone treatment, as others have previously shown. The adult height prediction in our group was slightly better for boys, all of whom are prepubertal, with a significantly greater predicted final adult height on the 17th centile compared with the third centile predicted for the untreated boys. The final height prediction for the girls also improved to the 13th centile. Our data indicate that the higher dose of growth hormone given to short normal children does promote growth without affecting the rate of bone age maturation.

It has been suggested that growth hormone treatment shortens the amplitude and the duration of the pubertal growth spurt, ${ }^{1819}$ which would result in no additional gain in final adult height but only a gain in earlier years. Other workers dispute this ${ }^{20}$ and in our present trial, four untreated girls just entered stage II puberty during the third year, as did four receiving treatment. There is, therefore, no indication in our study as yet that growth hormone is advancing the onset of puberty, nor is there any obvious relation between chronological age, bone age, and growth hormone treatment in the onset of puberty in these girls. During the next phase of the trial we shall be able to monitor the effect of this dose of growth hormone on the peak and duration of the pubertal growth spurt.

Concern was expressed in our first report of this study about changes in body composition. The loss in body fat noted in the first six months in the treated children was gradually regained over the following 18 months. The treated children remain leaner than the untreated group, however, and although they continue to lay down fat with growth, they have not caught up with the short controls.

Many workers have looked for factors that might predict the response to treatment. Brook et al state that pretreatment growth velocity is the major determinant of response to treatment. ${ }^{21} \mathrm{We}$ have found no such relation. It has been shown that height velocity measurements in the short term are imprecise and this was not used as a selection criteria for entry into the trial. ${ }^{22}$ Ranke et al have shown, in the analysis of children with 'idiopathic short stature' within the KIGS data set, $^{2}$ that the most important variables were younger age at the start of the treatment, higher growth hormone dose, and frequent daily injections. ${ }^{23}$ Clearly, these conditions are all met within our study. The children were fairly young at entry and similarly aged (mean 7.8 years). They all received six or seven daily injections each week and a relatively high dose of $30 \mathrm{IU} / \mathrm{m}^{2}$. If this is the optimum set of circumstances within the current state of knowledge, then our treated children should have the best chance of reaching a final height within the normal range. We have not, however, been able to identify any particular pretreatment variables or other factors in response to treatment which highlight responders. Concentrations of IGF-1 reliably increase in all those receiving treatment, and although this does not predict response, it may be a useful indicator of compliance.

Short normal children are sometimes referred to as children with idiopathic short stature. A precise and pure diagnosis in this group of children is difficult to ascertain and includes constitutional delay, familial short stature, and low birth weight. There is an overlap between constitutional delay and familial short stature, and it has not been found to be particularly helpful in determining response to treatment. $^{24}$ Therefore we have not subclassified our children and, in addition, our numbers are too small. Low birth weight was not one of the exclusion criteria for entry into the trial. Although there are two low birthweight children in each group, we have not excluded them from the analysis at this stage as they appear to be responding as well as the others in terms of growth.

Hyperinsulinaemia in children treated with growth hormone has been noted by several other workers, ${ }^{4825}$ but only reported during the first year or two of treatment, levels returning to normal thereafter, or at the end of treatment. The precise cause of the persisting mild hyperinsulinaemia that we have observed is uncertain, but may be related to the high dose of growth hormone. A number of factors may be involved. Growth hormone is known to act directly on the $\beta$ cell, ${ }^{26}$ thus increasing insulin production. It may also indirectly increase insulin by its effect on lipolysis, increasing hepatic glucose turnover and thus glucose stimulating insulin production. This has not been substantiated in short normal children, and although it theoretically may occur, the change in glucose turnover may be so small as to be difficult to measure. ${ }^{27}$ There is no evidence that prolonged hyperinsulinaemia is detrimental, but nor is there a good or appropriately comparable model.

In conclusion, we can confirm that growth hormone treatment has a positive effect on growth in short normal children in the short term, but, as has been stressed by others, the long term outcome in terms of final adult height and unwanted side effects is unknown. It is most important that longitudinal studies are completed and that final height data are collected. Secondly, we have noted persisting significant differences in body composition, with increased lean body mass, and also persisting hyperinsulinaemia in children treated with growth hormone. It is imperative that close monitoring, particularly of biochemical and body composition changes, is continually performed. Ultimately, we may be able to define specific treatment criteria, but further study is still required.

The authors gratefully acknowledge the support provided by Kabi Pharmacia UK Ltd and AB Sweden.

1 Underwood LE, Rieser PA. Is it ethical to treat healthy short children with growth hormone? Acta Paediatrica Scandinavica Suppl 1989; 362: 18-23. 
2 KIGS UK Collaborative Group. Kabi International growth study - United Kingdom report. Milton Keynes: Kabi Pharmacia, 1991.

3 Hindmarsh PC, Pringle PJ, Di Silvio L, Brook CGD. Effects of 3 years of growth hormone therapy in short normal children. Acta Paediatrica Scandinavica Suppl 1990; 366: 6-12.

4 Takano K, Hizuka N, Asakawa K, Sukegawa I, Horikawa R, Shizume $\mathrm{K}$. Effects of short-term growth hormone therapy in short children without growth hormone deficiency. Acta Paediatrica Scandinavica Suppl 1990; 366: 14-22.

5 Genentech Collaborative Study Group. Idiopathic shor stature: results of a one-year controlled study of human growth hormone treatment. F Pediatr 1989; 115: 713-9.

6 Cowell CT. Effects of growth hormone in short, slowly growing children without growth hormone deficiency.
Acta Paediatrica Scandinavica Suppl 1990; 366: 29-30.

7 Ackland FM, Jones J, Buckler JMH, Dunger DB, Rayner PHW, Preece MA. Growth hormone treatment in nongrowth hormone-deficient children: effects of stopping growth hormone-deficient children: effects of stopping
treatment. Acta Paediatrica Scandinavica Suppl 1990; 366: 32-7.

8 Lesage C, Walker J, Landier F, Chatelain P, Chaussain JL Bougneres PF. Near normalization of adolescent heigh with growth hormone therapy in very short children without growth hormone deficiency. F Pediatr 1991; 119: 29-34.

9 Walker JM, Bond SA, Voss LD, Betts PR, Wootton SA, Jackson AA. Treatment of short normal children with growth hormone - a cautionary tale? Lancet 1990; 336: growth hor

10 Tanner JM, Whitehouse RH, Takaishi M. Standards from birth to maturity for height, weight, height velocity, weight velocity; British children 1965. Arch Dis Child 1966; 41: 454-71

11 Tanner JM, Whitehouse RH, Cameron N, Marshall WA Healy MJR, Goldstein H. Assessment of skeletal maturity and prediction of adult height (TW2 method). London: Academic Press, 1983.

12 Brook CDG. Determination of body composition of children from skinfold measurements. Arch Dis Child 1971; 46: 182-4.

13 Siri WE. The gross composition of the body. Adv Biol Med Phys 4. New York: Academic Press, 1956: 239-80.

14 Tanner JM. Foetus into man. Ware: Castlemead Tanner JM. Foetus
Publications, 1989.
15 Rosenfeld RG, Frane J, Attie KM, et al. Six-year results of a randomized prospective trial of human growth hormone and oxandrolone in Turner syndrome. $\mathcal{F}$ Pediatr 1992; 121: $49-55$.

16 Johansson G, Sietnieks A, Janssens F, et al. Recombinan human growth hormone treatment in short children with chronic renal disease before transplantation or with funcchronic renal disease before trant in short children with tioning renal transplants: an interim report on five European studies. Acta Paediatrica Scandinavica Suppl

17 Hopwood NJ, Hintz RL, Gertner JM, et al. Growth response of children with non-growth-hormone deficiency and marked short stature during three years of growth hormone therapy. $\mathcal{F}$ Pediatr 1993; 123: 215-22.

18 Stanhope R, Albanese A, Hindmarsh P, Brook CGD. The effects of growth hormone therapy on spontaneous sexual development. Horm Res 1992; 38 (suppl 1): 9-13.

19 Darendeliler F, Hindmarsh PC, Preece MA, Cox L, Brook CGD. Growth hormone increases the rate of pubertal maturation. Acta Endocrinologica (Copenh) 1990; 122: 414-6.

20 Bourguignon JP. Growth and timing of puberty: reciprocal effects. Horm Res 1991; 36: 131-5.

21 Brook CDG, Hindmarsh PC, Smith PJ. The management of short stature. In: Brook CDG, ed. Clinical paediatric endrocrinology. Oxford: Blackwell Scientific, 1989: 118-27.

22 Voss LD, Wilkin TJ, Bailey BJR, Betts PR. The reliability of height and height velocity in the assessment of growth (the Wessex Growth Study). Arch Dis Child 1991; 66: 833-7.

23 Ranke MB, Guilbaud O, Lindberg A, Cole T. Prediction of the growth response in children with various growth disorders treated with growth hormone: analyses of data from the Kabi Pharmacia International Growth Study. from the Kabdiatr Suppl 1993; 391: 82-8.

24 Moore KC, Donaldson DI, Ideus PL, Gifford RA, Moor MV. Clinical diagnoses of children with extremely short stature and their response to growth hormone. $f$ Pediat 1993; 122: 687-92.

25 Hindmarsh PC, Brook CGD. Effect of growth hormone on short normal children. BMF 1987; 295: 573-7.

26 Rabinovitch A, Quigley C, Rechler MM. Growth hormone stimulates islet $\beta$-cell replication in neonatal rat pancreatic monolayer cultures. Diabetes 1983; 32: 307-12.

27 Walker J, Chaussain JL, Bougneres PF. Growth hormone treatment of children with short stature increases insulin secretion but does not impair glucose disposal. $\mathcal{f}$ Clin Endocrinol Metab 1989; 69: 253-8. 